\title{
Analogs of TIQ-A as inhibitors of human mono-ADP-ribosylating PARPs
}

\author{
Mirko M. Maksimainen ${ }^{a}$, Sudarshan Murthy ${ }^{a}$, Sven T. Sowa ${ }^{a}$, Albert Galera-Prat ${ }^{a}$, \\ Elena Rolina $^{\mathrm{a}}$, Juha P. Heiskanen ${ }^{\mathrm{b}}$, Lari Lehtiö ${ }^{\mathrm{a}, \text { " }}$ \\ ${ }^{\text {a }}$ Faculty of Biochemistry and Molecular Medicine \& Biocenter Oulu, University of Oulu, Oulu, Finland \\ ${ }^{\mathrm{b}}$ Research Unit of Sustainable Chemistry, Faculty of Technology, University of Oulu, Oulu, Finland
}

\section{A R T I C L E I N F O}

\section{Keywords:}

TIQ-A

ADP-ribosylation

ADP-ribosyltransferase

PARP

Structure-guided inhibitor design

\begin{abstract}
A B S T R A C T
The scaffold of TIQ-A, a previously known inhibitor of human poly-ADP-ribosyltransferase PARP1, was utilized to develop inhibitors against human mono-ADP-ribosyltransferases through structure-guided design and activity profiling. By supplementing the TIQ-A scaffold with small structural changes, based on a PARP10 inhibitor OUL35, selectivity changed from poly-ADP-ribosyltransferases towards mono-ADP-ribosyltransferases. Binding modes of analogs were experimentally verified by determining complex crystal structures with mono-ADPribosyltransferase PARP15 and with poly-ADP-ribosyltransferase TNKS2. The best analogs of the study achieved 10-20-fold selectivity towards mono-ADP-ribosyltransferases PARP10 and PARP15 while maintaining micromolar potencies. The work demonstrates a route to differentiate compound selectivity between mono- and poly-ribosyltransferases of the human ARTD family.
\end{abstract}

\section{Introduction}

Human PARP enzymes of the diphtheria toxin-like ADP-ribosyltransferasefamily (ARTD) ${ }^{1}$ form a group of 17 enzymes sharing a catalytic domain carrying out the post-translational protein modification called ADP-ribosylation. ${ }^{2-3}$ Based on the nature of the resulting modification, the family members are classified as poly-ADPribosyltransferases (poly-ART) or mono-ADP-ribosyltransferases (mono-ART). Poly-ARTs PARP1-2 and TNKS1-2 produce polymers of ADP-ribose (PAR) to target proteins, whereas most of the enzymes in the family are actually mono-ARTs which transfer single ADP-ribose units to a target. ADP-ribosylation regulates vital cellular processes like transcription, signaling and DNA repair and thus PARPs are possible therapeutic targets against human diseases, especially cancer.

The catalytic PARP domain contains a substrate $\mathrm{NAD}^{+}$binding site comprising both nicotinamide and adenosine binding pockets. Due to that, PARP inhibitors have been developed to target either one of the pockets or both. To date, clear majority of known PARP inhibitors are nicotinamide mimetics and the inhibitor development is more advanced against poly-ART members than mono-ART as the best PARP1-2 inhibitors olaparib, rucaparib, niraparib and talazoparib are already in clinical use. ${ }^{4,5}$ In addition, tankyrase inhibitor development has recently resulted in lead compounds showing promising antitumor activities. 6,7 In the case of mono-ADP-ribosyltransferases, approximately half of the members are lacking selective inhibitors. Based on the available literature, selective inhibitors have been discovered for PARP7, ${ }^{8}$ PARP $10,{ }^{9}$ PARP1 $1,{ }^{10}$ PARP14 ${ }^{11}$ and PARP15 $5^{12}$ but their usability in clinical treatments remains to be elucidated. A generally known challenge in the PARP inhibitor development is gaining of selectivity due to the conserved catalytic domain of PARPs.

Thieno[2,3-c] isoquinolin-5(4H)-one, also known as TIQ-A (1) was originally developed as a potential anti-ischemic agent inhibiting PARP $1 .{ }^{13,14}$ We recognized, while evaluating inhibitors against tankyrases, that $\mathbf{1}$ is indeed also a potent TNKS inhibitor. ${ }^{15}$ Notably, many early PARP inhibitors, including approved drugs, suffer from a lack of selectivity between the PARP family members. ${ }^{16}$ In the case of 1 , its poor selectivity is obvious as we have previously shown the compound is also efficient to inhibit mono-ART PARP15. ${ }^{9} \mathbf{1}$ belongs to nicotinamide mimicking inhibitors and partially resembles OUL35, a selective inhibitor of PARP10. ${ }^{17}$ From the structure activity relationship study of PARP10 inhibitors ${ }^{18}$ we identified an analog (2), which together with 1 formed a basis for our attempts to optimize the scaffold $\mathbf{1}$ in such a way that it would have selectivity towards different PARPs. A key feature of 2 is that it extends towards the acceptor site of the enzyme where protein to be modified is expected to bind. This region is more polar in polyARTs containing an active site glutamate required for PAR elongation reaction, while the corresponding residue in most mono-ARTs is a hydrophobic one. By using a selected set of both poly- and mono-ART

\footnotetext{
* Corresponding author.

E-mail address: lari.lehtio@oulu.fi (L. Lehtiö).
} 
PARPs as examples we demonstrate that the selectivity profile of 1 can be changed through appropriate substitutions and the differences can be explained to some extent using crystal structures of a poly-ART (TNKS2) or a mono-ART (PARP15) in complex with the inhibitors.

\section{Materials and methods}

\subsection{Chemistry}

The compounds 3-8 were synthesized during our previous studies. ${ }^{19}$ The syntheses of new molecules $\mathbf{9}$ and $\mathbf{1 0}$ are described below. All commercial starting materials and reagents were used without purification. The solvents were dried with appropriate molecular sieves when needed. The reaction progress was monitored with silica gel-coated aluminum TLC sheets. The chemical structures of $\mathbf{9}$ and $\mathbf{1 0}$ were characterized using ${ }^{1} \mathrm{H}$ NMR, ${ }^{13} \mathrm{C}$ NMR, and HRMS measurements. ${ }^{1} \mathrm{H}$ and ${ }^{13} \mathrm{C}$ NMR assignments of $\mathbf{9}$ and $\mathbf{1 0}$ are presented in the Figs. S1-S6. Purities of 4-8 were assessed using LCMS by UV absorbance and are $\geq$ 95\% unless otherwise stated.

Methyl 3-(3-ethoxyphenyl)thiophene-2-carboxylate (9). Compound 3 (137.2 mg; $586 \mathrm{mmol}$ ) and $\mathrm{K}_{2} \mathrm{CO}_{3}(292.0 \mathrm{mg} ; 2.11 \mathrm{mmol}$ ) were placed in a reaction tube. The sealed tube was evacuated and backfilled with argon three times. The mixture was stirred and heated in an oil bath $\left(65^{\circ} \mathrm{C}\right)$. Diethyl sulfate $(0.12 \mathrm{~mL} ; 918 \mathrm{mmol})$ was added. The reaction was allowed to proceed $18 \mathrm{~h}$. Water $(10 \mathrm{~mL})$ and EtOAc $(10 \mathrm{~mL})$ were added. The aqueous phase was extracted with EtOAc $(2 \times 10 \mathrm{~mL})$ and the combined organic phase was filtered through a thin pad of silica, which was rinsed with EtOAc. After evaporation, the sticky residue was washed with water $(3 \times 10 \mathrm{~mL})$ and dried under vacuum. The procedure afforded 9 as a sticky solid (142.0 mg) in $92 \%$ yield. ${ }^{1} \mathrm{H}$ NMR (400 MHz, $\left.\mathrm{CDCl}_{3}\right) \delta$ ppm $1.45(\mathrm{t}, J=7.0 \mathrm{~Hz}, 3 \mathrm{H}), 3.80(\mathrm{~s}, 3 \mathrm{H}), 4.08(\mathrm{q}, J=7.0 \mathrm{~Hz}$, 2H), 6.94 (ddd, $J=8.3,2.5,0.9 \mathrm{~Hz}, 1 \mathrm{H}$ ), 7.03-7.07 (m, 2H), 7.10 (d, $J=$ $5.1 \mathrm{~Hz}, 1 \mathrm{H}), 7.31-7.35(\mathrm{~m}, 1 \mathrm{H}), 7.50(\mathrm{~d}, J=5.1 \mathrm{~Hz}, 1 \mathrm{H}) .{ }^{13} \mathrm{C}$ NMR $(100$

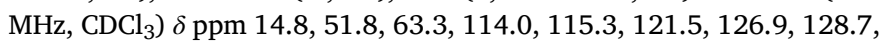
$130.1,131.5,136.8,148.3,158.3,162.3$. HRMS (ESI) $m / z:[\mathrm{M}+\mathrm{H}]^{+}$ Calcd for $\mathrm{C}_{14} \mathrm{H}_{15} \mathrm{O}_{3} \mathrm{~S}$ 263.0736; Found 263.0737.

8-Ethoxythieno [2,3-c] isoquinolin-5(4H)-one (10). Compound 9 $(142.0 \mathrm{mg}, 541 \mathrm{mmol})$ was added to a $100 \mathrm{~mL}$ round-bottom flask. EtOH (6.8 mL), $\mathrm{H}_{2} \mathrm{O}(6.8 \mathrm{~mL})$, and ground $\mathrm{NaOH}(433.0 \mathrm{mg}, 10.8 \mathrm{mmol})$ were added and the reaction mixture was refluxed for $90 \mathrm{~min}$. $\mathrm{CH}_{2} \mathrm{Cl}_{2}(15 \mathrm{~mL})$ was added to the cooled mixture. Aq. $\mathrm{HCl}(37 \%)$ was added dropwise until the $\mathrm{pH}$ value reached 2 . The aqueous phase was extracted with $\mathrm{CH}_{2} \mathrm{Cl}_{2}(2 \times 15 \mathrm{~mL})$. The combined organic phase was washed with water $(2 \times 10 \mathrm{~mL})$, dried $\left(\mathrm{Na}_{2} \mathrm{SO}_{4}\right)$ and filtered. The solvent was evaporated under vacuum to give the intermediate carboxylic acid as a white powder (136.0 mg; >99\%). The acid was transferred into a $50 \mathrm{~mL}$ twoneck round-bottom flask and dry toluene $(3.75 \mathrm{~mL})$ was added. The mixture was stirred at $80{ }^{\circ} \mathrm{C}$ under argon. Thionyl chloride $(0.07 \mathrm{~mL}$, $960 \mathrm{mmol}$ ) and dry DMF (few drops) were added. After $105 \mathrm{~min}$, the solvent and excess reagent were evaporated. THF $(3.0 \mathrm{~mL})$ was added under argon and the mixture was stirred at $0{ }^{\circ} \mathrm{C} . \mathrm{NaN}_{3}(52.7 \mathrm{mg}, 811$ $\mathrm{mmol})$ in $\mathrm{H}_{2} \mathrm{O}(0.45 \mathrm{~mL})$ was added slowly to the mixture. After $20 \mathrm{~min}$, ice-water $(10 \mathrm{~mL})$ and $\mathrm{CH}_{2} \mathrm{Cl}_{2}(10 \mathrm{~mL})$ were added. The phases were separated and the aqueous layer was extracted with $\mathrm{CH}_{2} \mathrm{Cl}_{2}(2 \times 10 \mathrm{~mL})$. The combined organic phase was dried $\left(\mathrm{Na}_{2} \mathrm{SO}_{4}\right)$ and filtered. The evaporation residue was dissolved in 1,2-dichlorobenzene $(4.5 \mathrm{~mL})$ and added to hot $\left(210^{\circ} \mathrm{C}\right) 1,2$-dichlorobenzene $(6 \mathrm{~mL})$ in a $50 \mathrm{~mL}$ two-neck round-bottom flask equipped with a reflux condenser and an argon balloon. The reaction mixture was stirred at $210{ }^{\circ} \mathrm{C}$ for $20 \mathrm{~h}$. The evaporation residue was dissolved in a mixture of toluene and EtOAc (1:1) and subjected to a flash chromatography using EtOAc as an eluent. The collected solid was washed with $n$-hexane $(3 \times 5 \mathrm{~mL})$, and dried to afford 10 as light-grey powder $\left(104.5 \mathrm{mg}\right.$ ) in $79 \%$ yield. ${ }^{1} \mathrm{H}$ NMR (400 $\left.\mathrm{MHz}, \mathrm{CDCl}_{3}\right) \delta \mathrm{ppm} 1.51(\mathrm{t}, J=7.0 \mathrm{~Hz}, 3 \mathrm{H}), 4.22(\mathrm{q}, J=7.0 \mathrm{~Hz}, 2 \mathrm{H})$, 7.00 (d, $J=5.6 \mathrm{~Hz}, 1 \mathrm{H}), 7.08$ (dd, $J=8.9,2.3 \mathrm{~Hz}, 1 \mathrm{H}), 7.26-7.27$ (m, $1 \mathrm{H}), 7.43$ (d, $J=5.6 \mathrm{~Hz}, 1 \mathrm{H}), 8.44(\mathrm{~d}, J=8.9 \mathrm{~Hz}, 1 \mathrm{H}), 11.37$ (br s, $1 \mathrm{H})$.
13C NMR (100 MHz, $\left.\left(\mathrm{CD}_{3}\right)_{2} \mathrm{SO}\right) \delta \mathrm{ppm} 14.5,63.7,105.6,115.0,116.2$, 116.9, 117.6, 121.5, 129.9, 135.6, 141.3, 161.0, 162.2. HRMS (ESI) $m / z$ : $[\mathrm{M}+\mathrm{H}]^{+}$Calcd for $\mathrm{C}_{13} \mathrm{H}_{11} \mathrm{NO}_{2} \mathrm{~S} 246.0583$; Found 246.0583 .

\subsection{Protein expression and purification}

All the proteins used in this study were expressed in E. coli and purified using our previously reported protocols. ${ }^{17}$ TNKS2 constructs were cloned into pNIC-MBP expression vectors and an additional purification on an MBPTrap HP $5 \mathrm{~mL}$ column (GE Healthcare) prior to cleavage with TEV protease was performed. ${ }^{20}$ Details of the constructs for each PARP enzyme are listed in Table S1.

\subsection{Activity assay}

Dose response experiments were performed using our previously reported activity assay for PARP enzymes. ${ }^{9,21}$ Half-log dilutions for the compounds were used and reactions were carried out in quadruplicates. $\mathrm{IC}_{50}$ curves were fitted using sigmoidal dose response curve (four variables) in GraphPad Prism version 5.04 (GraphPad Software). Details of the assay conditions of different PARP enzymes are available in Table S1.

\subsection{Crystallization}

Crystallization of TNKS2 and soaking with 7, 8 and $\mathbf{1 0}$ was done as previously described. ${ }^{22}$ PARP15 was co-crystallized with 1, 2, 4, 5, 6, 7, 8 and 10 utilizing the existing crystallization conditions for PARP15. ${ }^{23}$ Compounds were dissolved in DMSO and $1.5 \mu \mathrm{l}$ of resulting $10 \mathrm{mM}$ solution was gently mixed with $20 \mu \mathrm{l}$ of $10.5 \mathrm{mg} / \mathrm{ml}$ PARP15 and incubated for $30 \mathrm{~s}$ at $20{ }^{\circ} \mathrm{C}$ for crystallization. $100-150 \mathrm{nl}$ of a proteincompound solution was mixed well with $75-100 \mathrm{nl}$ of solution consisting of $0.2 \mathrm{M} \mathrm{NH}_{4} \mathrm{Cl} \mathrm{pH} \mathrm{7.5,} \mathrm{16-20 \%} \mathrm{(w/v)} \mathrm{PEG} 3350$ using the Mosquito crystallization robot (SPT Labtech) and 3 well low profile UVP (Swissci) for sitting drop vapour diffusion. Crystallization plates of PARP15 and TNKS2 were incubated at $+20{ }^{\circ} \mathrm{C}$ and $+4{ }^{\circ} \mathrm{C}$, respectively. All plates were imaged using the RI54 imager (Formulatrix) at the respective temperature and monitoring of crystallization was performed using the IceBear software. ${ }^{24}$ PARP15 crystals were obtained in $24 \mathrm{~h}$ while TNKS2 crystals were obtained in 5 days.

\subsection{Data collection, processing and refinement}

Prior to data collection, PARP15 crystals were cryoprotected with a solution consisting of $0.2 \mathrm{M} \mathrm{NH}_{4} \mathrm{Cl} \mathrm{pH} \mathrm{7.5,} \mathrm{30 \%} \mathrm{(v/v)} \mathrm{MPD} \mathrm{(2-methyl-}$ 2,4-pentanediol). TNKS2 crystals were soaked in reservoir solution containing $20 \%$ glycerol. The X-ray diffraction data were collected at the synchrotron facilities of DLS (Didcot, UK) and ESRF (Grenoble, France). All data were processed and scaled with the XDS program. ${ }^{25}$ The PARP15 and TNKS2 complex structures were solved by molecular replacement with Molrep ${ }^{26}$ (from the CCP4 package) ${ }^{27}$ using the previously reported structures of PARP15 (PDB accession code $3 \mathrm{BLJ}^{23}$ and TNKS2 (PDB accession code $50 \mathrm{WS}^{28}$.The PARP15 and TNKS2 models were refined with Refmac $5^{29}$ (from the CCP4 package) ${ }^{27}$ Visualization and building of all models were performed using Coot. ${ }^{30}$ The residues in PARP15 and TNKS2 models were numbered according to the canonical sequences of UniProt ${ }^{31}$ entries Q460N3-1 and Q9H2K2-1, respectively. Data collection and refinement statistics are shown in the Table S2.

\section{Results}

\subsection{Synthesis}

Compound 3 was alkylated with diethyl sulfate using solvent-free Williamson synthesis ${ }^{32}$ which gave 9 in high yield (Scheme 1). 8Ethoxythieno[2,3-c]isoquinolin-5(4H)-one $\mathbf{1 0}$ was synthesized 
<smiles>COC(=O)c1sccc1-c1cccc(O)c1</smiles>

3

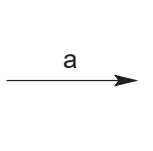<smiles>CCOc1cccc(-c2ccsc2C(=O)OC)c1</smiles>

$9(92 \%)$<smiles>CCOc1ccc2c(=O)[nH]c3sccc3c2c1</smiles>

$10(79 \%)$

Scheme 1. ${ }^{\mathrm{a}}$ Synthesis of 8-ethoxythieno [2,3-c]isoquinolin-5(4H)-one (10). ${ }^{\mathrm{a}}$ Reagents and conditions: (a) diethyl sulfate, $\mathrm{K}_{2} \mathrm{CO}_{3}, 65{ }^{\circ} \mathrm{C}, 18 \mathrm{~h}$; (b) $\mathrm{NaOH}, \mathrm{EtOH}, \mathrm{H}_{2} \mathrm{O}$, reflux, $90 \mathrm{~min}$; (c) $\mathrm{SOCl}_{2}$, toluene, DMF, $80{ }^{\circ} \mathrm{C}, 105 \mathrm{~min}$; (d) $\mathrm{NaN}_{3}$, THF, $\mathrm{H}_{2} \mathrm{O}$, ice bath, $20 \mathrm{~min}$; (e) 1,2-dichlorobenzene, $210{ }^{\circ} \mathrm{C}, 20 \mathrm{~h}$.

following the method developed during our previous studies. ${ }^{19}$ The base catalyzed hydrolysis of the ester group of 9 resulted an acid that was converted to its acid chloride with thionyl chloride and catalytic amount of dry DMF. Reaction with $\mathrm{NaN}_{3}$ gave the corresponding carbonyl azide, which readily underwent Curtius rearrangement at elevated temperature in 1,2-dichlorobenzene, affording 10 in good yield.

\subsection{Inhibitor design and structural studies}

Compound $\mathbf{1}$ is a nicotinamide mimicking compound, which we have previously reported to inhibit human TNKS2, a poly-ART, at a nanomolar potency $\left(\mathrm{IC}_{50}=24 \mathrm{nM}\right) .{ }^{15}$ In addition, while developing an activity-based assay for human mono-ADP-ribosyl-transferases, ${ }^{9}$ we saw that the compound also inhibited PARP15 $\left(\mathrm{IC}_{50}=232 \mathrm{nM}\right)$ and modestly

\section{Table 1}

Profiling of the compounds against a panel of human ARTs.<smiles>O=c1[nH]c2sccc2c2ccc(I)cc12</smiles><smiles>COCc1ccccc1</smiles><smiles>COCc1cccc(Br)c1</smiles>
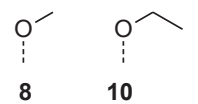

\begin{tabular}{|c|c|c|c|c|c|c|}
\hline ID & $\begin{array}{l}\text { PARP2 } \\
\text { IC }_{50} \\
\text { (pIC50 } \\
\pm \text { SEM) }\end{array}$ & $\begin{array}{l}\text { TNKS2 } \\
\text { IC }_{50} \\
\text { (pIC50 } \\
\pm \text { SEM) }\end{array}$ & $\begin{array}{l}\text { PARP10 } \\
\text { IC }_{50} \\
(\text { pIC50 } \pm \\
\text { SEM) }\end{array}$ & $\begin{array}{l}\text { PARP14 } \\
\text { IC } 50 \\
\text { (pIC50 } \pm \\
\text { SEM) }\end{array}$ & $\begin{array}{l}\text { PARP15 } \\
\text { IC } 50 \\
\text { (pIC50 } \pm \\
\text { SEM) }\end{array}$ & $\begin{array}{l}\text { PDB codes } \\
\text { of crystals } \\
\text { structures } \\
\text { (Enzyme) }\end{array}$ \\
\hline 1 & $210 \mathrm{nM}$ & $24 \mathrm{nM}^{*}$ & $>10 \mu \mathrm{M}^{*}$ & $>10 \mu \mathrm{M}$ & $230 \mathrm{nM}^{*}$ & $\begin{array}{l}\text { 7OQQ } \\
\text { (PARP15) }\end{array}$ \\
\hline 2 & $\begin{array}{l}>100 \\
\mu \mathrm{M}\end{array}$ & $\begin{array}{l}>100 \\
\mu \mathrm{M}\end{array}$ & $2.4 \mu \mathrm{M}$ & $630 \mathrm{nM}$ & $1.2 \mu \mathrm{M}$ & $\begin{array}{l}\text { 7OSP } \\
\text { (PARP15) }\end{array}$ \\
\hline 4 & $87 \mu \mathrm{M}$ & $57 \mu \mathrm{M}$ & $>10 \mu \mathrm{M}$ & $>100 \mu \mathrm{M}$ & $>10 \mu \mathrm{M}$ & $\begin{array}{l}\text { 7OSS } \\
\text { (PARP15) }\end{array}$ \\
\hline 5 & $1.2 \mu \mathrm{M}$ & $\begin{array}{l}130 \mathrm{nM} \\
(6.89 \pm \\
0.055)\end{array}$ & 4. $5 \mu \mathrm{M}$ & $>100 \mu \mathrm{M}$ & $1.4 \mu \mathrm{M}$ & $\begin{array}{l}\text { 7OSX } \\
\text { (PARP15) }\end{array}$ \\
\hline 6 & $60 \mu \mathrm{M}$ & $20 \mu \mathrm{M}$ & $>10 \mu \mathrm{M}$ & $>100 \mu \mathrm{M}$ & $\gg 10 \mu \mathrm{M}$ & $\begin{array}{l}\text { 7OTF } \\
\text { (PARP15) }\end{array}$ \\
\hline 7 & $19 \mu \mathrm{M}$ & $22 \mu \mathrm{M}$ & $2.4 \mu \mathrm{M}$ & $>100 \mu \mathrm{M}$ & $\begin{array}{l}1.1 \mu \mathrm{M} \\
(5.95 \pm \\
0.12)\end{array}$ & $\begin{array}{l}\text { 7OTH } \\
\text { (PARP15) } \\
\text { 7OLJ } \\
\text { (TNKS2) }\end{array}$ \\
\hline 8 & $1.8 \mu \mathrm{M}$ & $\begin{array}{l}160 \mathrm{nM} \\
(6.86 \pm \\
0.08)\end{array}$ & $780 \mathrm{nM}$ & $52 \mu \mathrm{M}$ & $\begin{array}{l}527 \mathrm{nM} \\
(6.28 \pm \\
0.03)\end{array}$ & $\begin{array}{l}\text { 7OUW } \\
\text { (PARP15) } \\
\text { 7OM1 } \\
\text { (TNKS2) }\end{array}$ \\
\hline 10 & $\begin{array}{l}>100 \\
\mu \mathrm{M}\end{array}$ & $4.7 \mu \mathrm{M}$ & $920 \mathrm{nM}$ & $>10 \mu \mathrm{M}$ & $2.1 \mu \mathrm{M}$ & $\begin{array}{l}\text { 7OUX } \\
\text { (PARP15) } \\
\text { 7OMC } \\
\text { (TNKS2) }\end{array}$ \\
\hline
\end{tabular}

* Data from literature: PARP $2{ }^{16}$, TNKS2 ${ }^{15}$, PARP $10^{9}$ and PARP15 ${ }^{9}$.
PARP10 ( $41 \%$ inhibition at $10 \mu \mathrm{M})$. The relatively high potency against PARP15 led us to hypothesize if 1 could be used as a scaffold to develop a selective inhibitor against mono-ADP-ribosylating PARP enzymes. However, based on the clear evidences on its unselectivity against human PARPs seen by us and also Wahlberg et al. ${ }^{16}$ (Table 1 ), the scaffold needed to be modified rationally to change the selectivity towards mono-ADP-ribosyltransferases. To facilitate the compound design, we determined the PARP15 crystal structure in complex with 1 (Fig. 1A) that showed the compound similarly bound into the nicotinamide binding pocket with three hydrogen bonds created by G560 and S599 compared to previously reported TNKS2 structure where three hydrogen bonds are created by G1032 and S1068 (Fig. 1B). ${ }^{15}$

We thought that an extension of the scaffold towards the so-called acceptor site identified by Ruf et al., ${ }^{33}$ would change the selectivity towards mono-ADP-ribosyl-transferases as we have previously seen in the case of PARP10 inhibitors. ${ }^{17,18}$ We chose $\mathbf{2}$ as a partner for $\mathbf{1}$ because the compound showed a reasonable potency against PARP15 $\left(\mathrm{IC}_{50}=1.2\right.$ $\mu \mathrm{M})$ and importantly did not show activity against poly-ARTs such as PARP2 and TNKS2 (Table 1). We determined the PARP15 crystal structure in complex with $\mathbf{2}$ that showed that the compound is bound with the same hydrogen bond interactions as $\mathbf{1}$ and it indeed extends towards the acceptor site (Fig. 1C). Especially regarding the inhibitor design, the bromophenyl moiety of $\mathbf{2}$ is clearly oriented towards the acceptor site. These observations encouraged us to merge the 3-bromophenylmethoxy from 2 to C-8 of the scaffold 1 (Fig. 1D).

In order to implement the idea, we started chemical synthesis ${ }^{19}$ from which we first obtained 4 and 5 before the desired compound 6 . The profiling of the compounds against PARP2, TNKS2, PARP10, PARP14, and PARP15 showed that 4 was not very potent against any enzyme whereas 5 inhibited PARP2, PARP10, and PARP15 with micromolar potencies, being most potent against TNKS2 $\left(\mathrm{IC}_{50}=115 \mathrm{nM}\right.$, Table 1$)$. Like 4, the desired compound 6 was not potent against any PARP. In fact, the compound had at least 100 -fold and 20-fold less activity compared to $\mathbf{1}$ and 2, respectively. Despite of low potencies of $\mathbf{4}$ and $\mathbf{6}$, we were able to determine PARP15 complex crystal structures, which revealed that all three compounds bind to PARP15 as we had hypothesized (Fig. 2A-C). The superimposition of 1, 2 and 6 based on the PARP15 complex structures showed small differences between the positions of the compounds (Fig. 2D). The superimposition of $\mathbf{1 ,} 2$ and $\mathbf{6}$ based on the PARP15 complex structures showed small differences between the positions of the compounds (Fig. 2D). The compound 6 has rotated in the binding pocket in comparison to the reference inhibitors causing for example differences in the positions of the sulfur $(0.7 \AA$ distance between $\mathbf{1}$ and $\mathbf{6}$ ) and bromine atoms ( $0.8 \AA$ distance between of $\mathbf{2}$ and $\mathbf{6}$ ). The rotation causes a subtle change in the compound orientation resulting in suboptimal weak interactions that could explain the poor potency of 6 .

As the benzyloxy moieties in the scaffold 1 clearly hindered the inhibition, we rationalized that smaller substituents could work better. We tested analogs containing isopropoxy (7), methoxy (8), and ethoxy (10) 


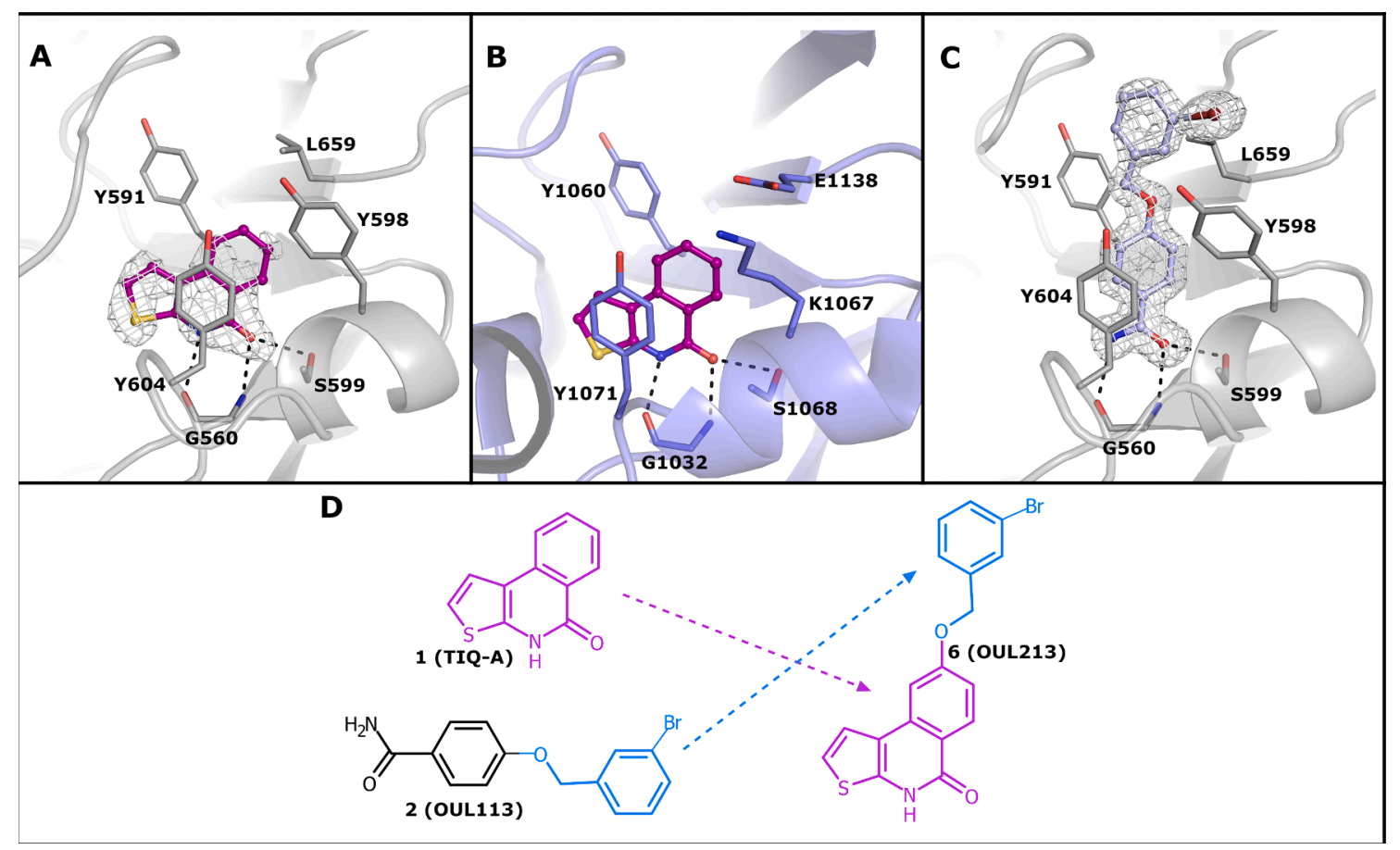

Fig. 1. Inhibitor design based on the complex structures of PARP15 and TNKS2. (A) PARP15 in complex with 1 (purple) (B) TNKS2 in complex with 1 (PDB id 4 AVW $)^{15}$ (C) PARP15 in complex with 2 (light blue) (D) Design to merge 1 and 2 to create a chimera 6 . Sigma A weighted omit Fo-Fc electron density maps covering the ligands in A and C are contoured at $3.0 \sigma$ and colored in white. Ligands are presented as ball-stick models while the residues of PARP15 and TNKS2 are presented as stick models and colored in grey and blue, respectively. The secondary structures of PARP15 and TNKS2 are presented as a grey and blue cartoon models, respectively. The hydrogen bonds are shown as black dashed lines. (For interpretation of the references to colour in this figure legend, the reader is referred to the web version of this article.)

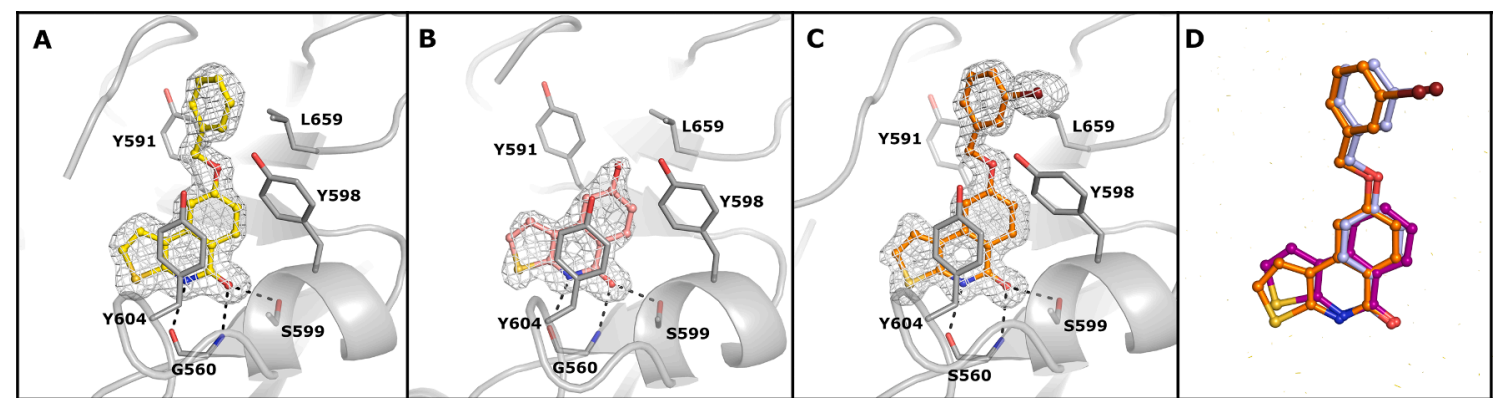

Fig. 2. PARP15 crystal structures in complex with (A) 4 (yellow) (B) 5 (pink) (C) 6 (orange) (D) Superimposition of 1 (purple), 2 (light blue) and 6 (orange) based on their PARP15 complex structures. For clarity, PARP15 is left out from the panel. The structures and electron density maps are presented as in Fig. 1. (For interpretation of the references to colour in this figure legend, the reader is referred to the web version of this article.)

substituents at C-8 of the scaffold 1. 7 showed approximately 10 -fold selectivity for PARP10 $\left(\mathrm{IC}_{50}=2.4 \mu \mathrm{M}\right)$ and 20 -fold selectivity for PARP15 $\left(\mathrm{IC}_{50}=1.1 \mu \mathrm{M}\right)$ over the poly-ARTs. 8 showed good potencies against PARP15 $\left(\mathrm{IC}_{50}=527 \mathrm{nM}\right)$ and PARP10 $\left(\mathrm{IC}_{50}=780 \mathrm{nM}\right)$ but lacked selectivity as it was also very active against TNKS2 $\left(\right.$ IC $_{50}=160$ $\mathrm{nM}) .10$ was not as good as $\mathbf{7}$ and showed approximately 5 -fold selectivity for PARP10 and 2-fold selectivity for PARP15 (Table 1). The complex crystal structures of $\mathbf{7}, \mathbf{8}$, and $\mathbf{1 0}$ showed that binding of the compounds is highly similar in both PARP15 and TNKS2 (Fig. 3). The orientations of methoxy and ethoxy moieties in PARP15 are clearly defined by the electron density maps while the isopropoxy moiety of $\mathbf{7}$ lacks clear electron density indicating mobility of the group in the binding pocket (Fig. 3A-C). In TNKS2, the compounds are well defined by electron density maps (Fig. 3D-F). A comparison of TNKS2 crystal structures reveal significant conformational changes of the sidechain of the catalytic residue, E1138 (Fig. 1B, 3D-F). This small rotation of E1138 is caused by the hydrophobic substituents that explain lower potency of $\mathbf{7}$ and $\mathbf{1 0}$ for TNKS2 (Table 1).

\section{Discussion}

Our aim was to develop selective inhibitors for human mono-ART class of PARP enzymes by utilizing the scaffolds of $\mathbf{1}$ and $\mathbf{2}$ and merging promising features through chemical synthesis. However, despite that the binding mode of hybrid analogs was experimentally verified to be same as planned, the direct combining the unique features of $\mathbf{1}$ and $\mathbf{2}$ did not work as relatively large benzyloxy moieties at C-8 of scaffold $\mathbf{1}$ resulted in significant loss of potency for all the PARPs used in the study. This could possibly be a result of subtle changes in the binding modes as in the co-crystal structures these analogs still maintained a highly similar binding mode (Fig. 2).

Instead, compounds 5, 7, 8 and 10 with smaller alkyloxy moieties at the same position showed micromolar or submicromolar potencies for both poly- and mono-ART enzymes. 7 containing an isopropoxy group 


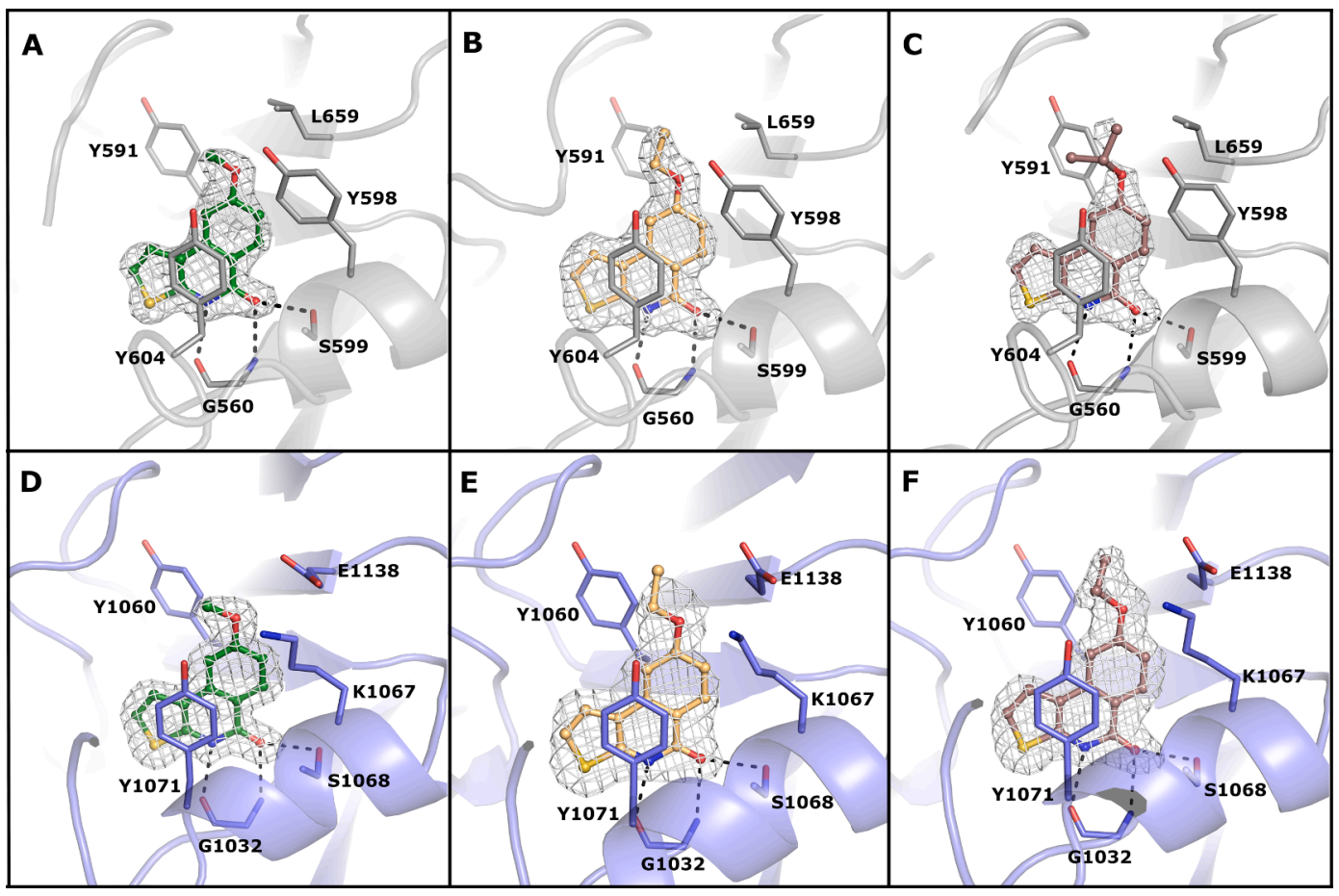

Fig. 3. Comparison of PARP15 and TNKS2 complex crystal structures (A) PARP15 in complex with 8 (B) PARP15 in complex with 10 (C) PARP15 in complex with 7 (D) TNKS2 in complex with 8 E) TNKS2 in complex with 10 (F) TNKS2 in complex with 7. The ligands 8, 10 and 7 are colored in green, light orange and brown, respectively. Sigma A weighted omit Fo-Fc electron density maps covering the ligands are presented as in Figs. 1 and 2. (For interpretation of the references to colour in this figure legend, the reader is referred to the web version of this article.)

showed the best selectivity (20-fold) for PARP15 in comparison to PARP2 and TNKS2 demonstrating a clear shift in selectivity towards mono-ARTs. The shift was structurally explained by the crystal structures, which revealed the compound induced conformational change of the catalytic residue of TNKS2. Selectivity boosts towards mono-ARTs induced by hydrophobic moieties extending towards the acceptor site has also be seen previously with PARP10 inhibitor development. ${ }^{18,34}$

This study is an example of a structure-based repurposing of a previously reported general inhibitor scaffold and making structure-based design of substituents enabling selectivity. In this report, we chose to study example enzymes to validate the strategy and it should be noted that there are 17 enzymes in the family and all of them have a conserved catalytic domain. Therefore, while further work is required, the strategy demonstrates ways to differentiate compound selectivity between mono- and poly-ART enzymes of the PARP family.

At the moment, very little is known about PARP15 despite that it is reported to be overexpressed in B-aggressive lymphoma ${ }^{35}$ and it is a potential therapeutic target in acute myeloid leukemia. ${ }^{36}$ The mechanism and contribution of this enzyme is however not clear. Some of the mono-ARTs have already become validated drug targets ${ }^{37}$ and therefore generation of potent inhibitors with differing selectivity profiles will hopefully facilitate the studies of these less proteins and the compounds reported here may be used as such tool compounds in the future.

\section{Funding}

This work was supported by the Academy of Finland (grant nos. 287063 and 294085 for LL), by Jane and Aatos Erkko foundation (for LL), by Sigrid Jusélius foundation (for LL), by Magnus Ehrnrooth foundation (for SM) and by the Emil Aaltonen foundation (for MMM).

\section{Data statement}

Atomic coordinates and structure factors have been deposited to the Protein Data Bank under accession numbers 7OLJ, 7OM1, 7OMC,
7OQQ, 7OSP, 7OSS, 7OSX, 7OTF, 7OTH, 7OUW and 7OUX, and raw diffraction images are available at IDA (https://doi.org/10.23729/39 42aada-8d3a-4391-87ed-2a88cf624d25).

\section{Declaration of Competing Interest}

The authors declare that they have no known competing financial interests or personal relationships that could have appeared to influence the work reported in this paper.

\section{Acknowledgements}

The authors would like to thank the staff of the beamlines ID23-1 and ID30A-1 in ESRF and I03 in DLS. The use of the facilities of the Biocenter Oulu Structural Biology core facility, a member of Biocenter Finland, Instruct-ERIC Centre Finland and FINStruct, is gratefully acknowledged.

\section{Appendix A. Supplementary material}

Supplementary data to this article can be found online at https://doi. org/10.1016/j.bmc.2021.116511.

\section{References}

1 Lüscher B, Ahel I, Altmeyer M, et al. ADP-ribosyltransferases, an update on function and nomenclature. FEBS J. 2021. https://doi.org/10.1111/febs.16142.

2 Otto H, Reche PA, Bazan F, et al. In silico characterization of the family of PARP-like poly(ADP-ribosyl)transferases (pARTs). BMC Genom. 2005;6:139. https://doi.org/ 10.1186/1471-2164-6-139.

3 Amé J-C, Spenlehauer C, de Murcia G. The PARP superfamily. BioEssays News Rev Mol Cell Dev Biol. 2004;26:882-893.

4 Pilié PG, Tang C, Mills GB, Yap TA. State-of-the-art strategies for targeting the DNA damage response in cancer. Nat Rev Clin Oncol. 2019;16:81-104.

5 Haddad G, Saadé MC, Eid R, Haddad FG, Kourie HR. PARP inhibitors: a tsunami of indications in different malignancies. Pharmacogenomics. 2020;21(3):221-230.

6 Waaler J, Leenders RGG, Sowa ST, et al. Preclinical Lead Optimization of a 1,2,4Triazole Based Tankyrase Inhibitor. J Med Chem. 2020;63:6834-6846. 
7 Plummer R, Dua D, Cresti N, et al. First-in-human study of the PARP/tankyrase inhibitor E7449 in patients with advanced solid tumours and evaluation of a novel drug-response predictor. Br J Cancer. 2020;123(4):525-533.

8 Gozgit JM, Vasbinder MM, Abo RP, et al. PARP7 negatively regulates the type I interferon response in cancer cells and its inhibition triggers antitumor immunity. Cancer Cell. 2021;39(9):1214-1226.e10.

9 Venkannagari H, Fallarero A, Feijs KLH, Lüscher B, Lehtiö L. Activity-based assay for human mono-ADP-ribosyltransferases ARTD7/PARP15 and ARTD10/PARP10 aimed at screening and profiling inhibitors. Eur J Pharm Sci. 2013;49:148-156.

10 Kirby IT, Kojic A, Arnold MR, et al. A Potent and Selective PARP11 Inhibitor Suggests Coupling between Cellular Localization and Catalytic Activity. Cell Chem Biol. 2018; 25:1547-1553.

11 Schenkel LB, Molina JR, Swinger KK, et al. A potent and selective PARP14 inhibitor decreases protumor macrophage gene expression and elicits inflammatory responses in tumor explants. Cell Chem Biol. 2021;28:1158-1168.

12 Yuen LH, Dana S, Liu Y, et al. A Focused DNA-Encoded Chemical Library for the Discovery of Inhibitors of NAD+-Dependent Enzymes. J Am Chem Soc. 2019;141: 5169-5181.

13 Chiarugi A, Meli E, Calvani M, et al. Novel isoquinolinone-derived inhibitors of poly (ADP-ribose) polymerase-1: pharmacological characterization and neuroprotective effects in an in vitro model of cerebral ischemia. J Pharmacol Exp Ther. 2003;305: 943-949.

14 Pellicciari R, Camaioni E, Costantino G, et al. Towards new neuroprotective agents: design and synthesis of $4 \mathrm{H}$-thieno[2,3-c] isoquinolin-5-one derivatives as potent PARP-1 inhibitors. Farmaco. 2003;58(9):851-858.

15 Haikarainen T, Narwal M, Joensuu P, Lehtiö L. Evaluation and Structural Basis for the Inhibition of Tankyrases by PARP Inhibitors. ACS Med Chem Lett. 2014;5(1): $18-22$.

16 Wahlberg E, Karlberg T, Kouznetsova E, et al. Family-wide chemical profiling and structural analysis of PARP and tankyrase inhibitors. Nat Biotechnol. 2012;30: 283-288.

17 Venkannagari H, Verheugd P, Koivunen J, et al. Small-Molecule Chemical Probe Rescues Cells from Mono-ADP-Ribosyltransferase ARTD10/PARP10-Induced Apoptosis and Sensitizes Cancer Cells to DNA Damage. Cell Chem Biol. 2016;23: $1251-1260$

18 Murthy S, Desantis J, Verheugd P, et al. 4-(Phenoxy) and 4-(benzyloxy)benzamides as potent and selective inhibitors of mono-ADP-ribosyltransferase PARP10/ARTD10. Eur J Med Chem. 2018;156:93-102.

19 Maksimainen MM, Nurmesjärvi A, Terho RA, Threadgill MD, Lehtiö L, Heiskanen JP. Derivatives of a PARP Inhibitor TIQ-A through the Synthesis of 8-Alkoxythieno[2,3c]isoquinolin-5(4H)-ones. ACS Omega. 2020;5(22):13447-13453.

20 Sowa ST, Vela-Rodríguez C, Galera-Prat A, et al. A FRET-based high-throughput screening platform for the discovery of chemical probes targeting the scaffolding functions of human tankyrases. Sci Rep. 2020;10:12357.
21 Haikarainen T, Murthy S, Maksimainen MM, Lehtiö L. Small-Molecule Screening Assay for Mono-ADP-Ribosyltransferases. Methods Mol Biol. 2018:1813:237-244.

22 Narwal M, Haikarainen T, Fallarero A, Vuorela PM, Lehtiö L. Screening and structural analysis of flavones inhibiting tankyrases. J Med Chem. 2013;56: 3507-3517.

23 Karlberg T, Klepsch M, Thorsell A-G, Andersson CD, Linusson A, Schüler H. Structural basis for lack of ADP-ribosyltransferase activity in poly(ADP-ribose) polymerase-13/zinc finger antiviral protein. J Biol Chem. 2015;290:7336-7344.

24 Daniel E, Maksimainen MM, Smith N, et al. IceBear: an intuitive and versatile web application for research-data tracking from crystallization experiment to PDB deposition. Acta Crystallogr Sect Struct Biol. 2021;77:151-163.

25 Kabsch W. Integration, scaling, space-group assignment and post-refinement. Acta Crystallogr D Biol Crystallogr. 2010;66:133-144.

26 Vagin A, Teplyakov A. Molecular replacement with MOLREP. Acta Crystallogr D Biol Crystallogr. 2010;66(1):22-25.

27 Winn MD, Ballard CC, Cowtan KD, et al. Overview of the CCP4 suite and current developments. Acta Crystallogr D Biol Crystallogr. 2011;67(4):235-242.

28 Nkizinkiko Y, Desantis J, Koivunen J, et al. 2-Phenylquinazolinones as dual-activity tankyrase-kinase inhibitors. Sci Rep. 2018;8:1680.

29 Murshudov GN, Skubák P, Lebedev AA, et al. REFMAC5 for the refinement of macromolecular crystal structures. Acta Crystallogr D Biol Crystallogr. 2011;67(4): 355-367.

30 Emsley P, Cowtan K. Coot: model-building tools for molecular graphics. Acta Crystallogr D Biol Crystallogr. 2004;60(12):2126-2132.

31 UniProt Consortium. UniProt: the universal protein knowledgebase in 2021. Nucleic Acids Res. 2021;49:D480-D489.

32 Massah AR, Mosharafian M, Momeni AR, Aliyan H, Nagash HJ, Adibnejad M. Solvent-Free Williamson Synthesis: An Efficient, Simple, and Convenient Method for Chemoselective Etherification of Phenols and Bisphenols. Synth Commun. 2007;37: $1807-1815$.

33 Ruf A, de Murcia G, Schulz GE. Inhibitor and NAD+ binding to poly(ADP-ribose) polymerase as derived from crystal structures and homology modeling. Biochemistry. 1998;37(11):3893-3900.

34 Morgan RK, Kirby IT, Vermehren-Schmaedick A, Rodriguez K, Cohen MS. Rational Design of Cell-Active Inhibitors of PARP10. ACS Med Chem Lett. 2019;10:74-79.

35 Aguiar RCT, Takeyama K, He C, Kreinbrink K, Shipp MA. B-aggressive lymphoma family proteins have unique domains that modulate transcription and exhibit poly (ADP-ribose) polymerase activity. J Biol Chem. 2005;280:33756-33765.

36 Lee MK, Cheong HS, Koh Y, Ahn K-S, Yoon S-S, Shin HD. Genetic Association of PARP15 Polymorphisms with Clinical Outcome of Acute Myeloid Leukemia in a Korean Population. Genet Test Mol Biomark. 2016;20:696-701.

37 Challa S, Stokes MS, Kraus WL. MARTs and MARylation in the Cytosol: Biological Functions, Mechanisms of Action, and Therapeutic Potential. Cells. 2021;10(2):313. https://doi.org/10.3390/cells10020313. 